\title{
Penerapan Sistem Informasi Pengelola Rantai Suplai (SI-PRS) dalam Mendukung Kegiatan Disektor Hulu Migas
}

\section{Application of the Supply Chain Manager Information System (SI- PRS) in Supporting the Upstream Oil and Gas Sector Activities}

\author{
Zahra Putri Deftya ${ }^{1 *}$, Santika Sari $^{2}$ \\ Jurusan Teknik Industri, Fakultas Teknik, Universitas “Veteran” Jakarta \\ Jl. Limo Cinere, Jakarta Selatan \\ Email: santika.sari@upnvj.ac.id, zahraaaptrr@gmail.com
}

\begin{abstract}
ABSTRAK
Pelaksanaan Pengadaan Barang dan Jasa adalah memperoleh dan menggunakan produk yang diperlukan dalam jumlah, kualitas, harga, waktu dan tempat secara tepat, efektif, efisien dan bertanggung jawab. Tujuan dari penelitian ini adalah untuk mengetahui kualitas sistem informasi dan memberikan kemudahan terhadap kepuasan dalam menggunakan aplikasi SI-PRS (Sistem Informasi Pengolahan Rantai Suplai). SI-PRS adalah aplikasi untuk mengelola pengadaan, rencana tender, hasil pelaksanaan tender, perubahan ruang lingkup pekerjaan dan laporan salinan kontrak dalam mendukung perusahaan SKK Migas. lebih lanjut, penelitian ini menyebarkan kuesioner dan analisis untuk mengukur perspektif pengguna dalam penggunaan SI-PRS dengan jumlah sampel 38 orang. beberapa pengujian meliputi uji validitas, uji reliabilitas, uji normalitas, uji multikolinearitas, uji heteroskedastisitas, uji t, uji f dan regresi linier untuk menentukan kepuasan pengguna SI-PRS. Kesimpulan penelitian ini menunjukan bahwa variabel Kualitas Sistem (X1), variabel Format(X2) dan Variabel Kemudahan (X3) secara parsial berpengaruh signifikan dan berpengaruh positif terhadap Kepuasand User (Y). kemudian, variabel X yang sangat dominan terhadap variabel Y (kepuasan user) adalah variabel kemudahan sebesar $42,6 \%$.
\end{abstract}

Kata Kunci: Sistem Informasi, Kualitas Sistem, Format, Kemudahan

\section{ABSTRACT}

The implementation of the procurement of goods and services is to obtain and use the required products in quantity, quality, price, time and place appropriately, effectively, efficiently and responsibly. The purpose of this study was to determine the quality of information systems and provide convenience to satisfaction in using the SI-PRS (Supply Chain Processing Information System) application. SI-PRS is an application for managing procurement, tender plans, results of tender implementation, changes in scope of work and contract copy reports in support of SKK Migas companies. Furthermore, this study distributed questionnaires and analyzes to measure the user's perspective in using the SI-PRS with a sample size of 38 people. Several tests include validity test, reliability test, normality test, multicollinearity test, heteroscedasticity test, $t$ test, $f$ test and linear regression to determine SI-PRS user satisfaction. The conclusion of this study shows that the System Quality variable (X1), the Format variable (X2) and the Ease Variable (X3) partially have a significant and positive effect on User Satisfaction (Y). Then, the variable X which is very dominant to the $\mathrm{Y}$ variable (user satisfaction) is the convenience variable of $42.6 \%$.

Keyword: System Information, System Quality, Format, Ease

\section{Pendahuluan}

Dunia kerja saat ini telah memiliki teknologi yang canggih. Teknologi informasi memiliki kelebihan yang bias membuat perusahaan diuntungkan dibanding menggunakan cara tradisional. Perkembangan teknologi memacu untuk memasuki era kehidupan. Di era sekarang semua teknologi sudah berbasis elektronik yang tujuannya untuk mempermudah semua pekerjaan. Dalam hal ini saya melaksanakan praktek kerja diperusahaan SKK Migas (Satuan Kerja Khusus Pelaksana Kegiatan Usaha Hulu Minyak dan Gas
Bumi), Divisi Pengelolaan Pengadaan Barang dan Jasa (PPBJ).

SKK Migas (Satuan Kerja Khusus Kegiatan Usaha Hulu Minyak dan Gas Bumi) merupakan institusi yang dibentuk oleh pemerintah. Pembentukan lembaga ini untuk menjadikan sumber daya alam migas milik negara yang dapat memberikan manfaat dengan hasil yang maksimal untuk sebesar-besarnya kemakmuran penduduk.

Tujuan pelaksanaan pengadaan barang / jasa adalah untuk mendapatkan dan menggunakan barang / jasa yang diperlukan dalam jumlah, kualitas, 
harga, waktu agar dapat beroperasi secara akurat, efektifitas, efisiensi dan penggunaan barang / jasa yang diperlukan dari segi waktu, kualitas, harga, waktu, dan secara adil, efektif dan efisien bagi perekonomian nasional (LKKP, 2018).

Dalam hal mewujudkan program pengelolaan rantai suplai, maka salah satu tugas yang perlu diperhatikan adalah dengan cara menggunakan sistem yang efektif dalam proses pengelolaan rantai suplai, (Agus. A. 2015). Dengan menggunakan cara traditional akan menurunkan tingkat keefektifan, membutuhkan banyak biaya dan terjadi banyak masalah sehingga perlu adanya perubahan. Sebelum tahun 2016 pengajuan persetujuan tender, rencana tender, hasil tender sampai pelaporan menggunakan sistem manual dengan cara pihak KKKS datang ke SKK Migas untuk memberikan dokumen yang berisi pengajuan persetujuan dan pelaporan. Lalu pengadaan memberikan kepada pejabat yang berwenang dalam menyetujui dokumen setelah dokumen tersebut disetujui laporan disimpan di map. Divisi pengadaan menyadari bahwa hal tersebut tidak efektif karena memerlukan banyak waktu,tenaga dan biaya terbuang.

Pada tahun 2016, diciptakan SI-PRS (Sistem Informasi Pengelolaan Rantai Suplai). Sistem ini mewujudkan program pengelolaan rantai suplai KKKS yang lebih cepat dan efisien karena sudah berupa online. Menurut Pujawa (2005), bahawa untuk mencapai komunikasi yang terintegrasi dalam suplay chain diperlukan teknologi-teknologi yang digunakan seperti Ekectronoic Data Interchange (EDI), Internet, Enterprise Resources Planning (ERP) dan Supply Chain Manajemen (SCM) sebagai software.

Sistem ini mempermudah KKKS untuk menginput dokumen pengajuan persetujuan procurement list yang akan dikirim ke SKK migas yang berupa output persetujuan hasil tender. Pihak KKKS (Kontraktor Kontrak Kerja Sama) hanya perlu memasukkan username dan password untuk menginput beberapa dokumen yang harus dikirim ke SKK Migas. Dokumen yang sudah disetujui oleh pejabat yang berwenang kemudian di scan diupload dan dikirim. Lalu dokumen yang sudah disetujui akan disimpan di database SI-PRS sehingga tidak membutuhkan map atau tempat untuk menaruh pelaporan tersebut. Sistem ini sudah berjalan \pm 4 tahun dan perlu adanya evaluasi tentang aplikasi ini. Hal tersebut membuat saya ingin meneliti tentang kepuasan pengguna SI-PRS.

Dalam penelitian ini membahas bagaimana faktor dari kualitas system. format (bentuk) dan kemudahan terhadap penggunaan SIPRS (Sistem Informasi Pengelolaan Rantai Suplai) yang terfokus dalam kepuasan user dalam menggunakan SIPRS. Hal ini saya lakukan untuk meningkatkan kepuasan user. Untuk mengetahui hal tersebut dilakukan dengan penelitian penyebaran kuesioner dan mengolah data dengan statistik deskriptif. Maka dari itu penulis melakukan penelitian mengenai "Analisis Penerapan Sistem Informasi Pengelolaan Rantai Suplai (SIPRS) dalam mendukung kegiatan disektor hulu migas"
Berdasarkan uraian latar belakang tersebut maka rumusan masalah dalam penelitian ini adalah Bagaimana hubungan mengenai kualitas sistem,format(bentuk) dan kemudahan dalam proses pengadaan terhadap tingkat kepuasan user dalam menggunakan aplikasi Sistem Informasi Pengelola Rantai Suplai (SIPRS)?

Adapun tujuan yang ingin disampaikan yakni Untuk mengetahui hubungan mengenai kualitas sistem, format(bentuk) dan kemudahan dalam proses pengadaan terhadap tingkat kepuasan user dalam menggunakan aplikasi Sistem Informasi Pengelola Rantai Suplai (SIPRS).

Untuk memperjelas masalah ini, Penelitian dilakukan dengan menganalisis yang sedang terjadi di Pengelolaan Pengadaan Barang dan Jasa di Satuan Kerja Khusus Pelaksana Kegiatan Usaha Hulu Minyak dan Gas Bumi (SKK Migas) pada aplikasi Sistem Informasi Pengelola Rantai Suplai (SIPRS) mengenai analisis Kualitas Sistem, Format (Bentuk), Kemudahan dalam kepuasan user dengan menggunakan software IBM SPSS versi 23.

\section{Metode Penelitian}

\section{Lokasi dan Jenis Penelitian}

Metode penelitian merupakan langkah yang dimiliki untuk memperoleh informasi atau data yang diinginkan peneliti tersebut dengan menggunakan penelitian kuantitatif. Yang dimaksud dengan kuantitatif adalah proses pencarian pengetahuan berupa data digital untuk menganalisis informasi tentang apa yang ingin diketahui oleh peneliti. Penelitian ini meneliti Satuan Kerja Khusus Pelaksanaan Hulu Minyak dan Gas Bumi (SKK Migas) di divisi Pengelolaan Pengadaan Barang dan Jasa dari 10 Februari sampai dengan 10 maret untuk menjelaskan pengaruh variabel kualitas sistem, format(bentuk) dan kemudahan tehadapat kepuasan user aplikasi SI-PRS.

\section{Kerangka Berfikir}

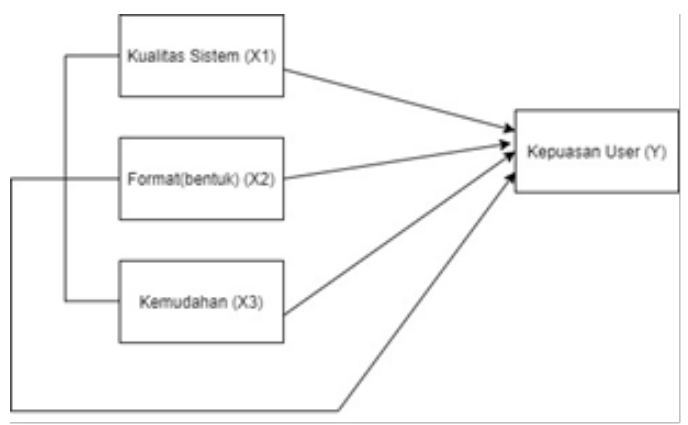

Gambar 1. Kerangka Berfikir

$\mathrm{H} 0=$ Kualitas sistem, format (bentuk) dan kemudahan tidak berpengaruh terhadap kepuasan user. 
$\mathrm{H} 1=$ Kualitas sistem berpengaruh terhadap kepuasan user

$\mathrm{H} 2=$ format (bentuk) berpengaruh terhadap kepuasan user.

$\mathrm{H} 3=$ kemudahan berpengaruh terhadap kepuasan user. H4=kualitas sistem, format(bentuk) dan kemudahan berpengaruh terhadap kepuasan user.

\section{Tahapan Penelitian}

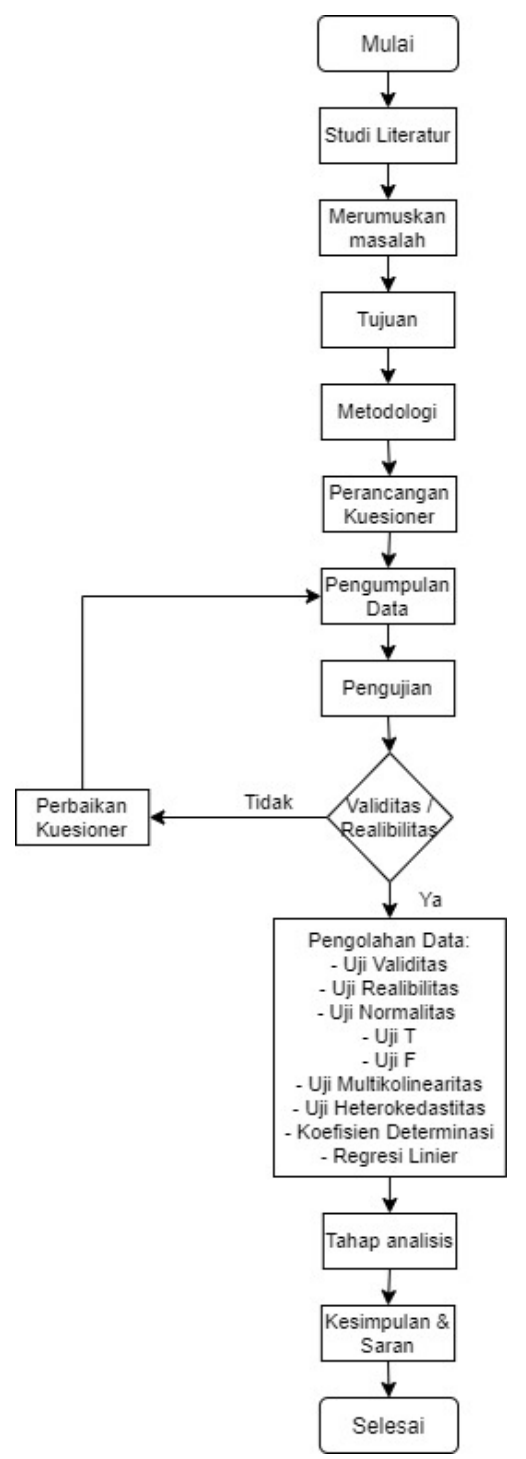

Gambar 2. Tahapan Penelitian

\section{Populasi dan Sampel}

Populasi menurut sugiyono (2013) mendefinisikan populasi adalah wilayah generasi yang terdiri dari objek yang mempunyai karateristik tertentu untuk ditetapkan oleh peneliti untuk dipelajari dan kemudian ditarik kesimpulan. Populasi dari penelitian ini adalah Kontraktor kontrak kerja sama (K3S) yang bekerjasama dengan divisi pengadaan barang dan jasa SKK Migas yang terdiri dari 60 .
Sampel menurut sugiyono (2002; 56) merupakan sebagian dan jumlah dan karakteristik yang dimiliki oleh populasi tersebut. Berdasarkan jumlah populasi yang sudah ditentukan maka jumlah sampel nya yaitu 38 . pemilihan sampel ini berdasarkan perhitungan penentuan sampel menggunakan rumus slovin.

\section{Teknik Pengumpulan Data}

Sumber data yang saya peroleh adalah data sekunder dengan cara mengumpulkan catatan atau dokumentasi dari perusahaan, media, web, internet, dll. Kemudian sumber data utama melalui wawancara dan kuesioner. Wawancara merupakan teknik yang tidak terstruktur, sehingga peneliti tidak menggunakan wawancara yang berisi pertanyaan-pertanyaan spesifik, melainkan hanya memuat poin-poin penting yang perlu diketahui dalam industri migas. Lalu penyebaran kuesioner dilakukan dengan cara tidak langsung diberikan menggunakan google form kepada pengguna yang mengakses aplikasi SI-PRS. Kuesioner ini menggunakan skala rating scale.

Tabel 1. Skala Jawaban

\begin{tabular}{|c|c|}
\hline Alternatif jawaban & Skor \\
\hline Sangat Setuju & 1 \\
\hline Setuju & 2 \\
\hline Cukup & 3 \\
\hline Tidak setuju & 4 \\
\hline Sangat Tidak setuju & 5 \\
\hline
\end{tabular}

Peneliti menggunakan uji validitas, realibilitas, uji normalitas, uji multikolinearitas, uji heteroskedastisitas, uji t, uji f, koefisien determinan dan regresi linier.

\section{Pengujian Instrumen \\ Analisa regresi berganda}

Menurut Ghozali (2018), analisis regresi linier berganda digunakan untuk mengetahui arah dan seberapa besar pengaruh variable independen terhadap variabel dependen

Alasan peneliti menggunakan regresi linier berganda adalah karena variabel yang diteliti memiliki hubungan yang linier antara variabel hipotetis, sehingga digunakan regresi berganda. Untuk rumus regresi linier berganda adalah

$$
\begin{aligned}
\mathrm{Y} & =\mathrm{a}+\mathrm{b} 1 \mathrm{X} 1+\mathrm{b} 2 \mathrm{X} 2+\mathrm{b} 3 \mathrm{X} 3+\mathrm{e} \\
& =1,201+0,347 \mathrm{X} 1+0,212 \mathrm{X} 2+0,426 \mathrm{X} 3+\mathrm{e}
\end{aligned}
$$

Dimana :

$\mathrm{Y}=$ variabel dependen atau kepuasan user

a $=$ konstanta

$\mathrm{X} 1=$ Kualitas Sistem 
$\mathrm{X} 2=$ Format

$\mathrm{X} 3=$ Kemudahan

$\mathrm{b}=$ Koefisien Regresi

$\mathrm{e}=$ error

\section{Hasil dan Pembahasan}

\section{Uji Validitas dan Realibilitas}

Berdasarkan hasil pengolahan diketahui bahwa pernyataan yang mempunyai nilai koefisien korelasi $\mathrm{r}$ hitung $\geq 0,3202$ untuk $\mathrm{N}=38-2$ dan $=0,05$ maka data tersebut dinyatakan valid. Untuk menguji validitas variabel produk / jasa dilakukan dengan menganalisis deklarasi yang memuat elemen pernyataan sebanyak 38 responden.. Contoh output hasil Validitas pernyataan variable format(X2) tersebut dapat dilihat pada tabel 2 .

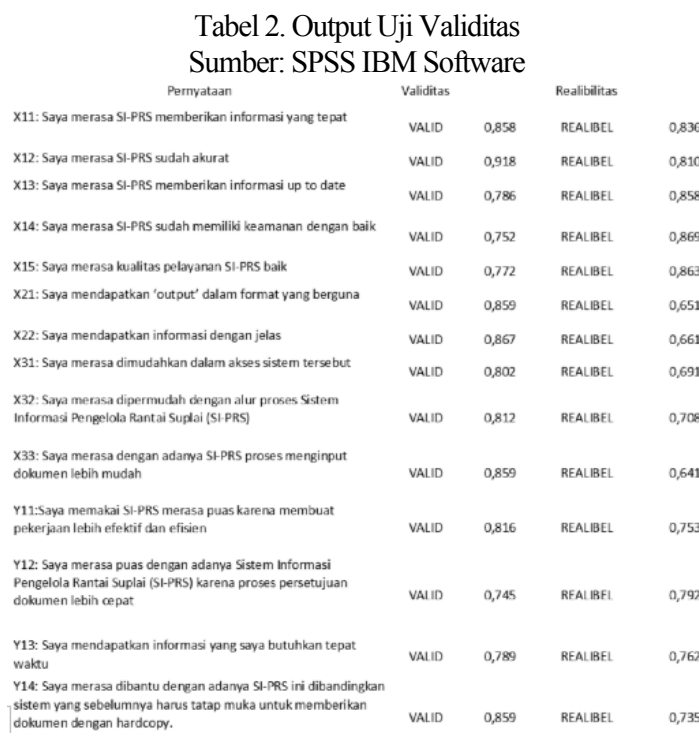

Dengan menguji reliabilitas instrumen dan instrumen yang digunakan Cronbach's Alpha. Jika pada uji reliabilitas didapatkan bahwa Cronbach's Alpha $\geq 0,60$, kita dapat menyimpulkan bahwa semua pernyataan pada variabel dinyatakan sangat reliabel.

Tabel 3. Output Realibilitas Sumber: SPSS IBM Software

\begin{tabular}{|r|c|c|c}
\multicolumn{2}{c}{ Reliability Statistics } \\
Cronbach's Alpha & N of Items \\
\hline 657 &
\end{tabular}

\section{Uji Normalitas}

Uji normalitas diatas menggunakan uji kolmogorov smirnov. Jika hasil output pengujian memiliki taraf signifikan $>0,05$ maka data berdistribusi normal. Jika output pengujian memiliki taraf signifikan $<0,05$. maka data tidak berdistribusi normal.

Tabel 4. Output Uji Normalitas

\begin{tabular}{|c|c|c|}
\hline \multicolumn{3}{|c|}{ One-Sample Kolmogorov-Smirnov Test } \\
\hline & & $\begin{array}{l}\text { Unstandardize } \\
\text { d Residual }\end{array}$ \\
\hline \multicolumn{2}{|l|}{$\mathrm{N}$} & 38 \\
\hline \multirow[t]{2}{*}{ Normal Parametersa, } & Mean & .0000000 \\
\hline & $\begin{array}{l}\text { Std. } \\
\text { Deviation }\end{array}$ & 1,59158191 \\
\hline \multirow{3}{*}{$\begin{array}{l}\text { Most } \\
\text { Differences }\end{array}$} & Absolute & .076 \\
\hline & Positive & 069 \\
\hline & Negative & -076 \\
\hline \multicolumn{2}{|l|}{ Test Statistic } & 076 \\
\hline \multicolumn{2}{|l|}{ Asymp. Sig. (2-tailed) } & $200^{\mathrm{c}, \mathrm{d}}$ \\
\hline
\end{tabular}

Berdasarkan tabel diatas maka dapat disimpulkan bahwa berdistribusi normal karena taraf signifikannya adalah 0,76 .

\section{Uji Multikolinearitas}

Uji Multikolinearitas dianalisis dengan tolerance bernilai $>0,05$ maka tidak terjadi multikolinearitas. Selain itu uji ini juga dapat dianalisa dari nilai VIF $<20$. maka data tidak terjadi multikolinearitas. Maka variabel X1, X2, X3 tidak terjadi multikolinearitas

Tabel 5. Output Uji Multikolineaitas Sumber : SPSS IBM Software

\begin{tabular}{|l|l|l|}
\hline Variabel & Tolerance & VIF \\
\hline $\mathrm{X} 1$ & 0,273 & 3,665 \\
\hline $\mathrm{X} 2$ & 0,316 & 3,163 \\
\hline $\mathrm{X} 3$ & 0,296 & 3,379 \\
\hline
\end{tabular}

Dari tabel diatas, terdapat tolerance dan nilai VIF dari setiap variabel yaitu variabel kualitas sistem (X1), Format (bentuk) (X2) dan variabel kemudahan (X3), semua tolerance semua variabel lebih besar dari 0,05 . dan juga nilai VIF yang semuanya lebih kecil dari 20 maka data tidak terjadi kemultikolinearitas.

Dalam uji ini, $\mathrm{t}$ tabel harus lebih kecil dari $\mathrm{t}$ hitung maka $\mathrm{H} 1, \mathrm{H} 2, \mathrm{H} 3$ dapat diterima. $\mathrm{T}$ tabel $=1,690$ yang didapat dari tabel $\mathrm{t}$ signifikansi $5 \%$ dan $\mathrm{df}=38-$ $4=34$. 
Tabel 6. Ouput Uji T

Sumber: SPSS IBM Software

\begin{tabular}{|l|l|}
\hline Variabel & T hitung \\
\hline $\mathrm{X} 1$ & 2,485 \\
\hline $\mathrm{X} 2$ & 1,860 \\
\hline $\mathrm{X} 3$ & 1,869 \\
\hline
\end{tabular}

Berdasarkan tabel dapat diketahui nilai t hitung:

- Dapat disimpulkan bahwa H1 diterima, artinya “ Kualitas sistem (X1) berpengaruh secara signifikan terhadap Kepuasan User (Y)"

- Dapat disimpulkan bahwa H2 diterima, artinya “ Format (bentuk) (X2) berpengaruh secara signifikan terhadap Kepuasan User (Y) “

- Dapat disimpulkan bahwa H3 diterima, artinya “ kemudahan (X3) berpengaruh secara signifikan terhadap Kepuasan User (Y) “

- Dapat disimpulkan bahwa variabel Kualitas Sistem (X1), variabel Format(X2) dan Variabel Kemudahan (X3) secara parsial berpengaruh signifikan terhadap Kepuasan User (Y).

\section{Uji F}

Dalam Penelitian ini didapatkan v1 $=4-1=3$ dan $\mathrm{v} 2=38-4=34$ sehingga $F$ tabel 2,88 Jika $F$ hitung lebih besar dari $\mathrm{F}$ tabel maka secara serentak variabel X berpengaruh kepada Variabel Y

Tabel 7. Output Uji F Sumber: SPSS IBM Software

\begin{tabular}{|c|c|c|c|c|c|c|}
\hline \multicolumn{7}{|c|}{ AsOXA: } \\
\hline \multicolumn{2}{|c|}{ Model. } & \multirow{2}{*}{$\begin{array}{l}\text { Sum of } \\
\text { Squares }\end{array}$} & \multirow{2}{*}{$\frac{\mathrm{df}}{3}$} & \multirow{2}{*}{$\begin{array}{l}\text { Mean } \\
\text { Square } \\
68,697\end{array}$} & \multirow{2}{*}{$\begin{array}{l}\mathrm{F} \\
24,920\end{array}$} & \multirow{2}{*}{$\frac{\text { Sig. }}{e 00^{b}}$} \\
\hline 1 & Regression & & & & & \\
\hline & Residual & 93,726 & 34 & 2,757 & & \\
\hline & Total & 299,816 & 37 & & & \\
\hline \multicolumn{7}{|c|}{ a. Dependent Variable: Y } \\
\hline & ictors: ( & ant), $\mathrm{X} 3, \mathrm{X}$ & $2, x i$ & & & \\
\hline
\end{tabular}

Dari tabel 7 output SPSS Uji F hitung = 24,920. Dengan $F$ tabel $=2,88$ dapat disimpulkan $F$ hitung $>\mathrm{F}$ tabel, yang berarti variabel kualitas sistem (X1), Variabel Format (X2) dan variabel kemudahan (X3) secara serempak berpengaruh signifikan terhadap variabel $\mathrm{Y}$.

\section{Koefisien Determinan}

Koefisien determinasi (R2) bertujuan untuk mengukur kapasitas model regresi dalam menjelaskan variasi variabel dependen. Hasil Uji koefisien determinasi dapat dilihat pada tabel dibawah ini.
Tabel 8. Output Koefisien Determinan

\begin{tabular}{|c|c|c|c|c|}
\hline \multicolumn{5}{|c|}{ Sumber:SPSS IBM Software } \\
\hline Model & $\mathrm{R}$ & R Square & $\begin{array}{ll}\text { Adjusted } & \text { R } \\
\text { Square } & \end{array}$ & $\begin{array}{l}\text { Std. Error of } \\
\text { the Estimate }\end{array}$ \\
\hline 1 & $829^{2}$ & 687. & 660 & 1,66031 \\
\hline
\end{tabular}

Dalam penelitian ini $68,7 \%$ dapat menjelaskan variable terikat tersebut.dan sisa dari angka tersebut yaitu $31,6 \%$ bisa diwakilkan oleh variabel lainnya dalam model regresi lainnya. Pada Koefisien Determinasi, bila bernilai kurang dari 0 maka tidak ada pengaruh dari variabel $\mathrm{X}$ dan $\mathrm{Y}$. Bila mendekati 1 maka pengaruh kuat. Dan bila mendekati 0 maka pengaruh semakin lemah

\section{Regresi Linier}

Berdasarkan tabel diatas dapat dilihat nilai konstata dan nilai koefisien variabel independen dari model regresi. didapatkan persamaan model regresinya, sebagai berikut:

$$
\begin{aligned}
& \mathrm{Y}=\mathrm{a}+\mathrm{b} 1 \mathrm{X} 1+\mathrm{b} 2 \mathrm{X} 2+\mathrm{b} 3 \mathrm{X} 3+\mathrm{e} \\
& =1,201+0,347 \mathrm{X} 1+0,212 \mathrm{X} 2+0,426 \mathrm{X} 3+\mathrm{e}
\end{aligned}
$$

Tabel 9. Output Uji Regresi Linier

\begin{tabular}{|c|c|c|c|c|c|}
\hline \multicolumn{6}{|c|}{ Coefficients: } \\
\hline \multirow[b]{2}{*}{ Model } & \multicolumn{2}{|c|}{$\begin{array}{l}\text { Unstandardized } \\
\text { Coefficients }\end{array}$} & \multirow{2}{*}{$\begin{array}{l}\text { Standardized } \\
\text { Coefficients } \\
\text { Beta }\end{array}$} & \multirow[b]{2}{*}{ t } & \multirow[b]{2}{*}{ Sig. } \\
\hline & B & Std. Error & & & \\
\hline (Constant) & 1,201 & 1,061 & & 1,132 & 265 \\
\hline $\mathrm{X} 1$ & 342 & 140 & 456 & 2,485 & $\Omega 18$ \\
\hline $\mathrm{X} 2$ & 212 & 372 & 295 & 552 & 580 \\
\hline $\mathrm{X} 3$ & 426 & 228 & 322 & 1,869 & sezo \\
\hline
\end{tabular}

Sumber: SPSS IBM Software

- Kualitas sistem , format dan kemudahan bernilai konstanta. Maka nilai kepuasan User adalah 1,201 .

- Besarnya pengaruh yang terdapat pada variabel kualitas system terhadap kepuasan pengguna (Y) adalah 0,347 dan berpengaruh positif, dimana penambahan suatu unit kualitas sistem akan mempengaruhi kepuasan pengguna 0,347 $(34,7 \%)$.

- Besarnya pengaruh yang terdapat pada variabel format terhadap kepuasan pengguna (Y) adalah 0,212 dan berpengaruh positif, dimana penambahan suatu unit format akan mempengaruhi kepuasan pengguna 0,212 ( 21,2 $\%)$.

- Besarnya pengaruh yang terdapat pada variabel kemudahan terhadap kepuasan pengguna (Y) adalah 0,426 dan berpengaruh positif, dimana penambahan suatu unit kemudahan akan 
mempengaruhi kepuasan pengguna 0.426 $(42,6 \%)$

- Maka dari ketiga variabel tersebut yang sangat dominan atau berpengaruh pada kepuasan user adalah variabel kemudahan. User merasa dimudahkan dalam akses dan dalam proses bisnis di aplikasi SI-PRS sehingga membuat user merasa puas. Maka terjadilah presetase paling besar adalah variabel kemudahan. Sedangkan berdasarkan data presentase terkecil adalah variabel format. Menurut user variabel format masih harus diimprove sehingga bisa membuat user lebih nyaman dalam menggunakan aplikasi ini.

\section{Kesimpulan}

Berdasarkan dari tujuan yang saya teliti ini yaitu mengetahui pengaruh kualitas sistem, Format(bentuk) dan kemudahan terhadap kepuasan user yang menggunakan aplikasi SI-PRS Setelah dilakukan pengujian data dan analisa, didapatkan kesimpulan sebagai berikut:

Kualitas Sistem berpengaruh terhadap Kepuasan User SI-PRS. Keluaran dari Regresi Linier, menunjukkan nilai koefisien regresi variabel kualitas sistem terhadap kepuasan user $(\mathrm{Y})$ berpengaruh secara positif sebesar 0,347 (34,7\%).

Format (bentuk) berpengaruh terhadap Kepuasan User SI-PRS. Keluaran dari Regresi Linier, menunjukkan nilai koefisien regresi variabel Format (bentuk) terhadap kepuasan user (Y) berpengaruh secara positif sebesar $0,212(21,2 \%)$

Kemudahan berpengaruh terhadap Kepuasan User SI-PRS Keluaran dari Regresi Linier, menunjukkan nilai koefisien regresi variabel Kemudahan terhadap Kepuasan User (Y) berpengaruh secara positif sebesar $0,426(42,6 \%)$.

Dari ketiga variabel tersebut yang paling dominan mempengaruhi kepuasan user SI-PRS adalah variabel kemudahan dengan besaran pengaruh $42,6 \%$.

\section{Saran}

Perlu adanya evaluasi bagi pihak perusahaan untuk kualitas sistem, format dan kemudahan dalam akses aplikasi SI-PRS. Hal ini dapat ditingkatkan dengan cara mengevaluasi keamanan untuk meningkatkan kenyamanan pengguna, Tatacara proses penggunaan SI-PRS. Penelitian ini hanya menggunakan 3 faktor yang mempengaruhi kepuasan user aplikasi Sistem Informasi Pengelola Rantai Suplai (SI-PRS) untuk itu perlu adanya penelitian lanjutan lagi dengan variabel yang lain agar dapat menjadi pengetahuan dan referensi untuk perusahaan agar dapat mengetahui kinerja proses pengadaan oleh SI-PRS ini.

\section{Ucapan Terima Kasih}

Terimakasih atas dukungan, semangat, serta bimbingan dari berbagai pihak, baik bersifat moril maupun materil, tanpa mereka saya tidak akan menyelesaikan laporan dengan cepat, oleh karena-Nya saya mengucapkan terimakasih sebanyak-banyaknya.

\section{Daftar Pustaka}

Agus, A. (2015). Supply Chain Management: The Influence of SCM on Production Performance and Product Quality. Journal of Economics, Business and Management, 1046-1053.

Pujawan, I Nyoman. (2005). Supply Chain Management. Surabaya: Guna widya.

LKKP. Tujuan, Kebijakan, Prinsip dan Etika PBJ Buku Informasi Versi: April 2018 Halaman: 35 dari 35

Gozali, I. (2018). Aplikasi Analisis Multivariate dengan Program IBM SPSS 25. Edisi 9. Semarang: Undip

Sugiyono. (2013)Metode Penelitian Pendidikan Pendekatan Kuantitatif, Kualitatif, da n R\&D. Bandung: Alfabeta. 